\title{
The importance of drug discovery for treatment of cardiovascular diseases
}

"Thus, the stepwise discovery of new therapeutic targets and the development of new, improved drugs led to substantial improvements in the treatment of hypertension and such a model is clearly applicable to other cardiovascular diseases."

Cardiovascular disease is the main cause of death across the world, accounting for approximately one third of all fatalities annually. This equates to approximately 17 million people dying each year from coronary heart disease and stroke in particular, as well as peripheral arterial disease and aortic disease [101]. In the UK coronary heart disease and stroke combined lead to approximately 131,000 deaths per year, or, on average, one death every $4 \mathrm{~min}[102,103]$. Furthermore, projections indicate that cardiovascular disease will kill nearly 25 million people globally by 2030 , maintaining its position as the leading cause of death. In addition to morbidity, cardiovascular disease impacts upon the quality of life of an even greater number people. For example, more than 1 million women and 1.6 million men in the UK have coronary heart disease [103], which can leave them feeling ill, tired and short of breath, which, in turn, greatly limits their ability to carry out everyday activities and live a full, normal life.

The most important behavioral risk factors for cardiovascular disease are smoking tobacco, an unhealthy diet, harmful use of alcohol, being overweight or obese and physical inactivity. For example, these account for approximately $80 \%$ of the incidence of coronary heart disease and cerebrovascular disease [101]. An immediate beneficial step in treating cardiovascular disease is to assess these risk factors and make changes in an individual's lifestyle to reduce them. Other risk factors, for example sex (men are more likely to develop cardiovascular disease at a younger age than women), age, ethnicity, family history, cannot, however, be modified. A change in lifestyle, whilst clearly beneficial, is, therefore, not necessarily enough to prevent the development of cardiovascular diseases or to manage them effectively where they have already developed. Cardiovascular risk in general can be reduced by inhibiting thrombus formation with lowdose aspirin, lowering blood cholesterol and inhibiting atherosclerosis with statins and lowering blood pressure, but there is a clear need for drugs that can specifically treat individual cardiovascular conditions.

At present the number of drugs available to treat individual cardiovascular diseases varies widely [104], and it is crucially important to identify new therapeutic targets in order to develop new, effective drugs. The history of the development of antihypertensive drugs is a good illustration of how combining chemistry, pharmacology and physiology can achieve this aim. Early research on this condition focused on vasodilators or on drugs that depressed sympathetic vasomotor input to blood vessels and the heart, such as ganglion blockers and adrenergic neuron blockers. Unsurprisingly, these drugs had many adverse side effects and they largely fell out of use following the discovery and characterization of multiple subtypes of adrenoceptors and the subsequent development of drugs that have a more focused action, such as selective $\alpha_{1}$-adrenoceptor antagonists, selective $\alpha_{2}$-adrenoceptor agonists and, ultimately, $\beta$-blockers, which were a primary treatment for hypertension for many years. The discovery and characterization of voltage-gated calcium ion channels, angiotensin-converting enzyme and angiotensin receptors then led to the development of selective calcium channel blockers, angiotensin-converting enzyme inhibitors and angiotensin-II receptor antagonists, which, along with diuretics and, to a lesser extent $\beta$-blockers, are now the frontline treatment for hypertension [104]. Thus, the stepwise discovery of new therapeutic targets and the development of new, improved drugs led to substantial improvements in the treatment of hypertension and such a model is clearly applicable to other cardiovascular diseases.

In the past 10-20 years our understanding of how the cardiovascular system works, and how its activity can be modulated by drugs,

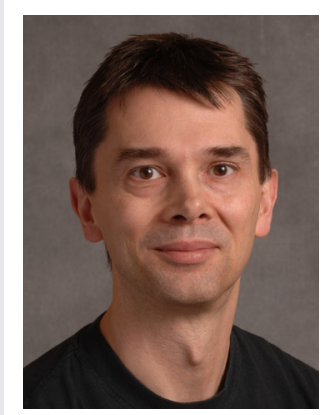

Charles Kennedy

Strathclyde Institute of Pharmacy \& Biomedical Sciences, University of Strathclyde, 161 Cathedral Street, Glasgow, G4 ORE, UK

Tel.: +44 I4| 5482664

Fax: +44 I4I 5522562

E-mail: c.kennedy@strath.ac.uk 
has expanded greatly due to the development of molecular biology techniques for the cloning, expression and deletion of proteins, such as receptors, enzymes and ion channels, combined with substantial advances in techniques that enable us to image and record changes in cellular activity. In addition, high-throughput screening of drug libraries, combined with synthetic chemistry, has made it easier to identify drugs that act on cardiovascular cells and has ensured the faster development of more potent and selective ligands. These technological advances have contributed to the introduction of new classes of drugs, including angiotensin-II receptor antagonists to treat hypertension and the cardiac ion channel blockers ivabradine and ranolazine to treat angina [104]. Thus, there is clearly great potential for further improving and refining the treatment of individual cardiovascular diseases through advanced drug discovery.

\section{"Furthermore, projections indicate that cardiovascular disease will kill nearly 25 million people globally by 2030, maintaining its position as the leading cause of death."}

This special focus issue features a number of contributions from authors across industry and academia. There are opinion-based pieces regarding the medicinal chemistry efforts on $\mathrm{NO}$ - and CO-releasing drug molecules [1,2], as well as discussions relating to whether cardiomyocytes are the right platform for testing cardiotoxicity in preclinical candidates [3]. Yin and $\mathrm{Hu}$ provide their view on the link between breast cancer and cardiovascular disease, and the implications of designing new small-molecule drugs [4]. Minnerup and Kleinschnitz analyze the risk and benefit of antithrombotic drugs [5], and Kleschyov and Sen' look at the potential of heparin derivatives for diagnosis and treatment [6]. There is also an interview with William Greenlee in which he discusses how he became involved in cardiovascular disease drug discovery, the initial challenges he faced and the ever-changing IP landscape [7].

In their Perspective, Sawicki et al. view the possible synergistic protection of myosin light chain 1 against cardiac ischemia/reperfusioninduced degradation as a therapeutic approach for the future [8]. There are further Perspectives by Ruf and colleagues who look ahead to the possible use of cathepsin A inhibitors [9], while Mehanna provides an overview of the past, present and future of antidiabetic medicinal chemistry in his article [10].

Kennedy and colleagues review targeting the nucleotide receptors for cardiovascular diseases, highlighting vasospasm, congestive heart failure and cardiac damage during ischemic episodes as viable targets [11]. Villamena and Zamora's Review discusses the pharmacological approaches to oxidative stress [12], and Hirsch and co-workers analyze the use of PI3K inhibitors [13]. The issue is rounded off with the final review by Baillie $e t a l$. in which the potential of targeting protein-protein interactions is discussed [14].

We would like to thank all of the authors and reviewers for their contribution to this special focus issue and hope that you enjoy the issue!

\section{Financial \& competing interests disclosure}

The author has no relevant affiliations or financial involvement with any organization or entity with a financial interest in or financial conflict with the subject matter or materials discussed in the manuscript. This includes employment, consultancies, honoraria, stock ownership or options, expert testimony, grants or patents received or pending, or royalties.

No writing assistance was utilized in the production of this manuscript.

\section{References}

1 Bhardwaj A, Kaur J, Knaus E. Can nitric oxide-releasing hybrid drugs alleviate adverse cardiovascular risks? Future Med. Chem. 5(4), 381-383 (2013).

2 Foresti R, Motterlini R. CO-releasing molecules: avoiding toxicity and exploiting the beneficial effects of $\mathrm{CO}$ for the treatment of cardiovascular disorders. Future Med. Chem. 5(4), 367-369 (2013).

3 Zeevi-Levin N, Itskovitz-Eldor J, Binah O. Functional cardiomyocytes from human stem cells: a tool for determining the cardiotoxic potential of preclinical drugs. Future Med. Chem. 5(4), 363-366 (2013).

4 Yin L, Hu Q. Drug discovery for breast cancer and co-instantaneous cardiovascular disease: what is the future? Future Med. Chem. 5(4), 359-362 (2013).

5 Minnerup J, Kleinschnitz C. No risk, no benefit: still true for antithrombotic stroke treatments? Future Med. Chem. 5(4), 377-379 (2013).

6 Kleschyov A, Sen' V. Heparin-polynitroxide derivatives: a platform for new diagnostic and therapeutic agents in cardiovascular disease? Future Med. Chem. 5(4), 385-388 (2013).
$7 \quad$ Greenlee W. Drug discovery and development in the field of cardiovascular disease. Future Med. Chem. 5(4), 375-376 (2013).

8 Cadete V, Arcand S, Lin H-B, Sawicki G. Synergistic protection of myosin light chain 1 against cardiac ischemia/reperfusion-induced degradation: a novel therapeutic concept for the future. Future Med. Chem. 5(4), 389-398 (2013).

9 Ruf S, Buning C, Schreuder $\mathrm{H}$ et al. Inhibiton of CatA: an emerging strategy for the treatment of heart failure. Future Med. Chem. 5(4), 399-409 (2013). 
10 Mehanna A. Antidiabetic agents, past, present and future. Future Med. Chem. 5(4), 411-430 (2013).

11 Kennedy C, Chootip K, Mitchell C, Syed $\mathrm{N}-\mathrm{i}-\mathrm{H}$, Tengah A. P2X and P2Y nucleotide receptors as targets in cardiovascular disease. Future Med. Chem. 5(4), 431-449 (2013).

12 Zamora P, Villamena F. Pharmacological approaches to the treatment of oxidative stress-induced cardiovascular dysfunctions. Future Med. Chem. 5(4), 465-478 (2013).

13 Ghigo A, Morello F, Perino A, Hirsch E. Therapeutic applications of PI3K inhibitors in cardiovascular diseases. Future Med. Chem. 5(4), 479-492 (2013).

14 Lee L, Maurice D, Baillie G. Targeting protein-protein interactions within the cyclic AMP signaling system as a therapeutic strategy for cardiovascular disease. Future Med. Chem. 5(4), 451-464 (2013).

\section{- Websites}

101 World Health Organisation. Cardiovascular diseases.

www.who.int/mediacentre/factsheets/fs317/ en/index.html
102 British Heart Foundation. Cardiovascular disease.

www.bhf.org.uk/heart-health/conditions/ cardiovascular-disease.aspx

103 NHS Choices. Cardiovascular disease. www.nhs.uk/conditions/Cardiovasculardisease/Pages/Introduction.aspx

104 British National Formulary. Cardiovascular system.

www.bnf.org/bnf/index.htm 